\title{
PEMBUATAN DAN UJI STABILITAS FISIK GEL SIMPLISIA DAUN KETEPENG CINA (Cassia alata L.) DENGAN BASIS GEL LIDAH BUAYA (Aloe vera L.)
}

\author{
Siti Nurhayati1 Dewi Ratnasari $^{2 *}$, Reti Puji Handayani ${ }^{3}$ \\ 1,2,3 Sekolah Tinggi Ilmu Kesehatan Holistik \\ *Korespondensi: Jl. Veteran No. 272 Ciseureuh Purwakarta, Email: dewiratnasari@stikesholistic.ac.id
}

\begin{abstract}
ABSTRAK
Latar Belakang: Panu merupakan penyakit kulit yang dapat diobati dengan bahan alam, salah satunya dengan daun ketepeng cina yang biasa digunakan oleh masyarakat Desa Blanakan. Sayangnya, belum ada sediaan alami yang praktis dan awet dalam penyimpanannya.

Tujuan Penelitian: Penelitian ini bertujuan untuk mengetahui cara pembuatan sediaan gel dari daun ketepeng cina dengan basis gel daun lidah buaya dan untuk mengetahui formulasi yang stabil berdasarkan uji stabilitas fisik pada suhu kamar $\left(15-30^{\circ} \mathrm{C}\right)$ dan suhu dingin $\left( \pm 4^{\circ} \mathrm{C}\right)$.

Metode: Desain penelitian ini menggunakan penelitian tindakan dengan instrumen penelitian berupa studi pustaka dan lembar pengamatan. Sediaan dibuat dari serbuk simplisia daun ketepeng cina dan gel lidah buaya dengan komposisi F I (0,5 gram, 5 gram), F II (0,5 gram, 10 gram), dan F III (0,5 gram, 15 gram).

Hasil: Formula terbaik sesaat setelah proses pembuatan dilihat berdasarkan uji organoleptik adalah F I. Berdasarkan uji stabilitas fisik, sediaan yang stabil secara pH dan organoleptik adalah FI yang disimpan pada suhu dingin $\left( \pm 4^{\circ} \mathrm{C}\right)$ dengan perubahan $\mathrm{pH}$ dari $6-4$, perubahan bau khas simplisia daun ketepeng menjadi khas lidah buaya, warna hijau coklat pekat, tekstur licin, bentuk semi solid, dan dapat bertahan selama 8 hari. Adapun sediaan yang memenuhi kriteria daya sebar adalah FII yang disimpan pada suhu kamar $\left(15-30^{\circ} \mathrm{C}\right)$.

Simpulan: Berdasarkan uji pH dan organleptik, formula yang cukup stabil adalah F I dengan 0,5 gram serbuk simplisia dan 5 gram gel lidah buaya sedangkan sediaan yang memenuhi kriteria daya sebar adalah FII yang disimpan pada suhu kamar $\left(15-30^{\circ} \mathrm{C}\right)$.
\end{abstract}

Kata kunci: Gel daun ketepeng cina, Lidah buaya sebagai basis gel, Panu

\begin{abstract}
Background: Pityriasis versicolor is a skin disease that can be treated with natural ingredients, one of them with leaves Cassia alata commonly used by the people of the Village Blanakan. Unfortunately, there has been no preparation of the natural which is practical and durable in storage.

Objective: This Study aims to find out how to make the preparation of the gel of the leaves Cassia alata $L$ with a base gel of aloe and to find out the stable formulation based on the physical stability test at room temperature $\left(15-30^{\circ} \mathrm{C}\right)$ and cold temperature $\left( \pm 4^{\circ} \mathrm{C}\right)$.

Method: The research design using action research a research instrument in the form of literature study and observation sheet. Preparations made from the crude drug of leaves ketepeng china and aloe vera gel with the composition of the F I (0,5 grams, 5 grams), F II (0,5 grams, 10 grams), dan $F$ III (0,5 grams, 15 grams).

Results: The best Formula shortly after the manufacturing process is viewed based on the organoleptic test is a F I. Based on the test of physical stability, the preparation is stable for $\mathrm{pH}$ and organoleptic is the FI that are stored at cold temperatures $\left( \pm 4^{\circ} \mathrm{c}\right)$ with the change of $\mathrm{pH}$ from 6-4, the change of the characteristic smell of crude leaves of cassia alata to be the typical aloe vera, the color green brown dense, sleek texture, form semi-solid, and can last for 8 days. As for the dosage forms that meet the criteria for coverage is the FII which are stored at room temperature $\left(15-30^{\circ} \mathrm{C}\right)$. Conclusion: Based on the test, the formula is quite stable is F I with 0.5 grams of the simplicia powder and 5 grams of aloe vera gel while preparations which meet the criteria for coverage is the FII which are stored at room temperature $\left(15-30^{\circ} \mathrm{C}\right)$.
\end{abstract}

Keywords: Gel of leaves ketepeng cina, Aloe vera as a gel base, Pityriasis versicolor 


\section{PENDAHULUAN}

Negara Indonesia merupakan negara tropis yang menjadi sasaran empuk bagi tumbuhnya jamur, seperti panu (Pityriasis versikolor) yang disebabkan oleh (Malassezia furfur). Selama ini, banyak orang berfikir bahwa panu hanya dapat diobati oleh obat sintesis padahal kenyataannya panu dapat diobati dengan bahan alam. Hal ini telah dilakukan oleh masyarakat di Desa Blanakan yang menggunakan daun ketepeng cina muda untuk mengobati panu dengan cara menggosokan ke bagian kulit tubuh yang terdapat panu.

Aktivitas ekstrak daun ketepeng cina (Cassia alata L.) sebagai antijamur telah dibuktikan oleh beberapa hasil penelitian. Salah satunya penelitian yang melaporkan bahwa ekstrak daun ketepeng cina (Cassia alata L.) dengan konsentrasi $50 \%$ sebanding dengan ketokonazol 2\% dalam menghambat pertumbuhan Malassezia furfur pada Pityriasis versicolor secara in vitro. ${ }^{[1]}$

Berdasarkan penelitian sebelumnya, basis yang digunakan pada pembuatan sediaan gel adalah CMC-Na. ${ }^{[2]}$ CMC-Na biasa digunakan dalam bidang obat-obatan sebagai pengental, stabilisator, pembentuk gel, dan pengemulsi.[3] Pada penelitian ini CMC-Na akan diganti dengan gel daun lidah buaya sebagai gelling agent dan moisturizer karena mengandung mucilago dan mukopolisakarida. ${ }^{44][5][6]}$

Penelitian ini bertujuan untuk mengetahui cara pembuatan sediaan gel dari serbuk simplisia daun ketepeng cina (Cassia alata L.) dengan menggunakan basis gel daun lidah buaya (Aloe vera L.) yang mudah dan praktis. Selain pembuatan, dilakukan uji stabilitas fisik untuk mengetahui formulasi yang tepat, aman, dan stabil berdasarkan $\mathrm{pH}$, daya sebar, dan uji organoleptik, yaitu mengamati warna, bentuk, bau, dan rasa. Pengamatan dilakukan setiap hari pada suhu kamar $\left(15-30^{\circ} \mathrm{C}\right)$ dan suhu dingin $\left( \pm 4^{\circ} \mathrm{C}\right)$.

\section{METODE PENELITIAN}

Penelitian ini dilaksanakan di Laboratorium STIKes Holistik Purwakarta pada Mei sampai dengan Agustus 2019. Desain penelitian yang digunakan adalah penelitian tindakan. Kegiatan yang dilakukan yaitu proses pembuatan sediaan dan uji stabilitas fisik. Proses pembuatan sediaan meliputi pembuatan simplisia dengan metode pengeringan, pembuatan gel lidah buaya serta formulasi. Adapun uji stabilitas fisik yang dilakukan adalah uji $\mathrm{pH}$, organoleptik, dan daya sebar.

\section{ALAT DAN BAHAN}

Alat yang digunakan dalam penelitian ini adalah ayakan mess 100, beaker glass $50 \mathrm{ml}$, blender, mortir dan stemper, panci, ph meter, cawan petri, desikator, oven, pot salep, saringan, spatula, sudip, termometer, timbangan digital, tube gel, dan kaca arloji.

Bahan yang digunakan dalam pembuatan gel adalah daun ketepeng cina (Cassia alata L.) yang tumbuh liar di Desa Blanakan dan lidah buaya (Aloe vera $L$.) yang diambil dari daerah Ciasem.

\section{CARA KERJA}

\section{Pembuatan Serbuk Simplisia Daun Ketepeng Cina (Cassia alata L.)}

Cuci bersih daun ketepeng cina (Cassia alata L.), kemudian dirajang lalu dijemur selama satu minggu, setelah itu, haluskan daun ketepeng cina (Cassia alata $L$.), kemudian ayak daun ketepeng cina (Cassia alata L.)..[7]

\section{Susut Pengeringan Simplisia Daun Ketepeng Cina (Cassia alata L.)}

Siapkan 3 cawan petri, timbang kemudian catat hasilnya, masukan 5 gram simplisia ke dalam cawan lalu oven cawan berisi simplisia pada suhu $105^{\circ} \mathrm{C}$ selama 1 jam, setelah 1 jam, tiriskan cawan menggunakan desikator selama 30 menit, setelah 30 menit timbang cawan dan catat hasilnya, hitung menggunakan rumus:

Susut Pengeringan

Keterangan :

$$
=\frac{\left(W_{0}+W_{1}\right)-W_{2}}{W_{1}} \times 100 \%
$$

$\mathrm{W}_{0} \quad$ = berat cawan kosong

$\mathrm{W}_{1} \quad=$ berat simplisia

$\mathrm{W}_{2}=$ berat cawan + simplisia setelah pengovenan

\section{Pembuatan Gel Lidah Buaya (Aloe vera L.)}

Cuci daun lidah buaya (Aloe vera L.) segar, potong-potong dan kupas lalu ambil dagingnya, setelah itu haluskan daging lidah buaya (Aloe vera L.), kemudian pekatkan. ${ }^{[8]}$ 
Formulasi Sediaan Gel Simplisia Daun Ketepeng Cina

Formulasi sediaan gel serbuk simplisia daun ketepeng cina (Cassia alata L.) dengan basis gel daun lidah buaya (Aloe vera L.) dibuat menjadi tiga formulasi, setiap formulasi dibuat menjadi 2 sediaan. Sediaan A untuk uji stabilitas pada suhu kamar(15$30^{\circ} \mathrm{C}$ ), sedangkan sediaan $\mathrm{B}$ untuk uji stabilitas pada suhu dingin $\left( \pm 4^{\circ} \mathrm{C}\right)$.

Tabel 1 Formulasi Sediaan

\begin{tabular}{|c|c|c|c|}
\hline \multirow{2}{*}{ Bahan } & \multicolumn{3}{|c|}{ Formula } \\
\hline & I & II & III \\
\hline $\begin{array}{r}\text { Serbuk simplisia daun } \\
\text { ketepeng cina (Cassia alata L.) }\end{array}$ & gram & 0,5 gram & 0,5 gram \\
\hline $\begin{array}{l}\text { Gel lidah buaya (Aloe } \\
\text { vera } L \text { ) }\end{array}$ & 5 gram & 10 gram & 15 gram \\
\hline
\end{tabular}

\section{Pembuatan Sediaan Gel :}

Timbang serbuk simplisia daun ketepeng cina (Cassia alata L.) dan gel lidah buaya (Aloe vera $L$ ) secara terpisah, masukan gel lidah buaya (Aloe vera $L$ ) ke dalam mortir, lalu tambahkan serbuk daun ketepeng cina (Cassia alata L.) sedikit demi sedikit, aduk hingga homogen. Setelah itu, tuang sediaan ke dalam pot salep, lakukan pengecekan $\mathrm{pH}$ sebagai $\mathrm{pH}$ awal, simpan gel A pada suhu kamar $\left(15-30^{\circ} \mathrm{C}\right)$ sedangkan gel $B$ pada suhu dingin $\left( \pm 4^{\circ} \mathrm{C}\right)$, lakukan pengamatan.

\section{UJI STABILITAS FISIK}

Uji $\mathrm{pH}$ dilakukan dengan cara memasukkan $\mathrm{pH}$ universal ke dalam sediaan. Tujuannya adalah mengukur derajat keasaman pada gel untuk menjamin sediaan gel tidak menyebabkan iritasi pada kulit. $\mathrm{pH}$ sediaan yang memenuhi kriteria $\mathrm{pH}$ kulit yaitu dalam interval 4,5-6,5. [9]

Organoleptik, formula daun ketepeng cina (Cassia alata L.) diuji stabilitasnya dengan mengamati warna, bentuk, bau, dan rasa.[10] Bentuk fisik yang diinginkan yaitu berwarna hijau transparan, semi solid, bau khas daun ketepeng cina, dan tidak licin

Uji daya sebar dilakukan untuk menjamin pemerataan gel saat diaplikasikan pada kulit. Gel ditimbang sebanyak 0,5 gram lalu diletakkan ditengah kaca bulat. Di atas gel ditimpa kaca bulat lain yang sudah ditimbang terlebih dahulu dan ditambahkan pemberat sehingga berat kaca bulat dan pemberat 150 gram. Setelah itu, didiamkan selama 1 menit, kemudian dicatat diameter penyebarannya. Daya sebar gel yang baik antara 5-7 cm. [11]

\section{HASIL PENELITIAN \\ Hasil Formulasi}

Formulasi yang dibuat dengan komposisi serbuk simplisia ketepeng cina dan gel daun lidah buaya diantaranya F I 0,5 gram serbuk simplisia : 5 gram gel daun lidah buaya), F II ( 0,5 gram serbuk simplisia : 10 gram gel daun lidah buaya), dan F III (0,5 gram serbuk simplisia : 15 gram gel daun lidah buaya). Hasil menunjukkan bahwa formula terbaik sesaat setelah proses pembuatan dilihat berdasarkan uji organoleptik adalah F I. Selain itu, F I juga merupakan formula paling stabil berdasarkan uji $\mathrm{pH}$ dan organoleptik yang dilakukan pada suhu kamar $\left(15-30^{\circ} \mathrm{C}\right)$ dan suhu dingin $\left( \pm 4^{\circ} \mathrm{C}\right)$. Adapun formula yang memenuhi kriteria daya sebar adalah F II.

\section{Hasil Susut Pengeringan}

Hasil uji susut pengeringan terhadap simplisia daun ketepeng cina (Casia alata) tertera pada Tabel 2 di bawah ini: 
Journal of Holistic and $\mathrm{Health}$ Sciences

Vol.3, No.2, Juli-D e s e mber 2019 |78

Tabel 2 Hasil Susut Pengeringan Simplisia Daun Ketepeng Cina (Cassia alata L.)

\begin{tabular}{|c|c|c|c|}
\hline \multirow{2}{*}{ Keterangan } & \multicolumn{3}{|c|}{ Cawan } \\
\cline { 2 - 4 } & A & B & C \\
\hline Berat cawan kosong & 99,29 gram & 92,47 gram & 102,71 gram \\
\hline Berat simplisia & 5,00 gram & 5,00 gram & 5,00 gram \\
\hline Berat cawan + simplisia & 104,29 gram & 97,47 gram & 107,71 gram \\
\hline Penimbangan 1 & 104,10 gram & 97,30 gram & 107,55 gram \\
\hline Penimbangan 2 & 104,08 gram & 97,29 gram & 107,54 gram \\
\hline Penimbangan 3 & 104,06 gram & 97,27 gram & 107,52 gram \\
\hline Rata-rata setiap cawan & $4,20 \%$ & $3,67 \%$ & $3,46 \%$ \\
\hline Rata-rata seluruhnya & \multicolumn{4}{|c}{$3,77 \%$} \\
\hline
\end{tabular}

Berdasarkan data diatas, susut pengeringan yang diperoleh dari 3 sampel simplisia daun ketepeng cina (Cassia alata L.) menunjukkan hasil presentase yang berbeda yaitu $4,20 \%$ untuk sampel A, 3,67\% untuk sampel B, dan 3,46\% untuk sampel C.

\section{Uji stabilitas fisik \\ Hasil uji pH}

Hasil uji pH dapat dilihat pada Gambar 2 dan Gambar 3 di bawah ini:

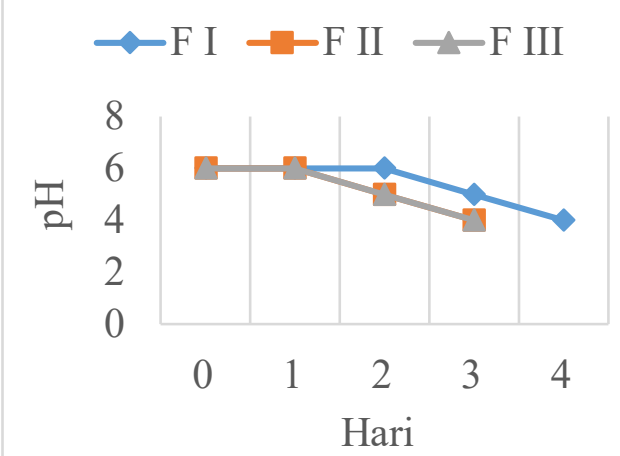

Gambar 2. Hasil Uji pH Pada Suhu

Kamar (15-30C)

\section{Hasil uji organoleptic}

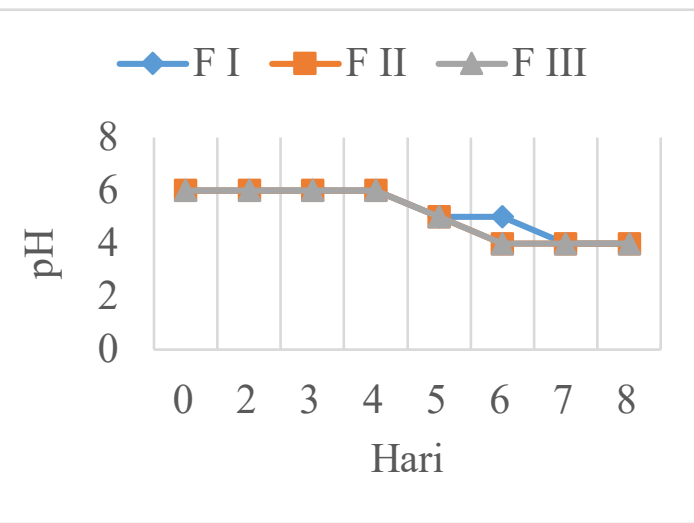

Gambar 3. Hasil Uji pH Pada Suhu Dingin

$$
\left( \pm 4^{\circ} \mathrm{C}\right)
$$

Hasil uji organoleptik tertera pada Tabel 3. (suhu kamar $\left(15-30^{\circ} \mathrm{C}\right)$ ) dan Tabel 4. (suhu dingin $\left.\left( \pm 4^{\circ} \mathrm{C}\right)\right)$ di bawah ini:

Tabel 3 Pengamatan Sediaan Pada Suhu Kamar (15-30C)

\begin{tabular}{|c|c|c|c|c|c|c|}
\hline \multirow{3}{*}{ Formula } & $\begin{array}{c}\text { Parameter } \\
\text { yang } \\
\text { diamati }\end{array}$ & $\mathbf{0}$ & $\mathbf{1}$ & $\mathbf{2}$ & $\mathbf{3}$ \\
\cline { 2 - 6 } & Warna & $\begin{array}{c}\text { Hijau kecoklatan } \\
\text { pekat }\end{array}$ & $\begin{array}{c}\text { Hijau kecoklatan } \\
\text { pekat }\end{array}$ & $\begin{array}{c}\text { Hijau kecoklatan } \\
\text { pekat }\end{array}$ & $\begin{array}{c}\text { Hijau kecoklatan } \\
\text { pekat }\end{array}$ & $\begin{array}{c}\text { Hijau kecoklatan } \\
\text { pekat }\end{array}$ \\
\cline { 2 - 6 } F I & Bau & $\begin{array}{c}\text { Khas ketepeng } \\
\text { cina }\end{array}$ & $\begin{array}{c}\text { Khas ketepeng } \\
\text { cina }\end{array}$ & $\begin{array}{c}\text { Khas ketepeng } \\
\text { cina }\end{array}$ & Khas lidah buaya & Khas lidah buaya \\
\cline { 2 - 7 } & Bentuk & Semi solid & Semi solid & Semi solid & Gel agak encer & Berjamur \\
\cline { 2 - 7 } & Rasa & Licin & Licin & Licin & Licin \\
\hline \multirow{2}{*}{ F II } & Warna & Hijau kecoklatan & Hijau kecoklatan & Hijau kecoklatan & Hijau kecoklatan & - \\
\hline
\end{tabular}


Journal of Holistic and $\mathrm{Health}$ Sciences

Vol.3, No.2, Juli-D e s e m b e r $2019 \mid 79$

\begin{tabular}{|c|c|c|c|c|c|c|}
\hline & Bau & $\begin{array}{l}\text { Khas ketepeng } \\
\text { cina }\end{array}$ & $\begin{array}{l}\text { Khas ketepeng } \\
\text { cina }\end{array}$ & Khas lidah buaya & Khas lidah buaya & - \\
\hline & Rasa & Licin & Licin & Licin & - & - \\
\hline \multirow{3}{*}{ F III } & Warna & $\begin{array}{c}\text { Hijau kecoklatan } \\
\text { pudar }\end{array}$ & $\begin{array}{c}\text { Hijau kecoklatan } \\
\text { pudar }\end{array}$ & $\begin{array}{c}\text { Hijau kecoklatan } \\
\text { pudar }\end{array}$ & $\begin{array}{c}\text { Hijau kecoklatan } \\
\text { pudar }\end{array}$ & - \\
\hline & Bau & $\begin{array}{l}\text { Khas ketepeng } \\
\text { cina }\end{array}$ & $\begin{array}{l}\text { Khas ketepeng } \\
\text { cina }\end{array}$ & Khas lidah buaya & Khas lidah buaya & - \\
\hline & Rasa & Licin & Licin & Licin & - & - \\
\hline
\end{tabular}

Tabel 4 Pengamatan Sediaan Pada Suhu Dingin $\left( \pm 4^{\circ} \mathrm{C}\right)$

\begin{tabular}{|c|c|c|c|c|c|c|}
\hline \multirow[b]{2}{*}{ Formula } & \multirow{2}{*}{$\begin{array}{l}\text { Parameter } \\
\text { yang } \\
\text { diamati }\end{array}$} & \multicolumn{5}{|c|}{ Hari } \\
\hline & & 0 & 2 & 4 & 6 & 88 \\
\hline \multirow{4}{*}{ F I } & Warna & $\begin{array}{c}\text { Hijau kecoklatan } \\
\text { Pekat }\end{array}$ & $\begin{array}{l}\text { Hijau kecoklatan } \\
\text { pekat }\end{array}$ & $\begin{array}{l}\text { Hijau kecoklatan } \\
\text { pekat }\end{array}$ & $\begin{array}{l}\text { Hijau kecoklatan } \\
\text { pekat }\end{array}$ & $\begin{array}{c}\text { Hijau kecoklatan } \\
\text { pekat }\end{array}$ \\
\hline & Bau & $\begin{array}{c}\text { Khas ketepeng } \\
\text { cina }\end{array}$ & $\begin{array}{c}\text { Khas ketepeng } \\
\text { cina }\end{array}$ & Khas lidah buaya & Khas lidah buaya & Khas lidah buaya \\
\hline & Bentuk & Semi solid & Semi solid & Gel mengerut & Gel mengerut & Berjamur sedikit \\
\hline & Rasa & Licin & Licin & Licin & Licin & - \\
\hline \multirow{4}{*}{ F II } & Warna & Hijau kecoklatan & Hijau kecoklatan & Hijau kecoklatan & Hijau kecoklatan & Hijau kecoklatan \\
\hline & Bau & $\begin{array}{l}\text { Khas ketepeng } \\
\text { cina }\end{array}$ & $\begin{array}{l}\text { Khas ketepeng } \\
\text { cina }\end{array}$ & Khas lidah buaya & Khas lidah buaya & Khas lidah buaya \\
\hline & Bentuk & Semi solid & Semi solid & Gel mengerut & Gel mengerut & Berjamur banyak \\
\hline & Rasa & Licin & Licin & Licin & Licin & - \\
\hline \multirow{4}{*}{ F III } & Warna & $\begin{array}{l}\text { Hijau kecoklatan } \\
\text { pudar }\end{array}$ & $\begin{array}{c}\text { Hijau kecoklatan } \\
\text { pudar }\end{array}$ & $\begin{array}{l}\text { Hijau kecoklatan } \\
\text { pudar }\end{array}$ & $\begin{array}{c}\text { Hijau kecoklatan } \\
\text { pudar }\end{array}$ & $\begin{array}{c}\text { Hijau kecoklatan } \\
\text { pudar }\end{array}$ \\
\hline & Bau & $\begin{array}{l}\text { Khas ketepeng } \\
\text { cina }\end{array}$ & $\begin{array}{l}\text { Khas ketepeng } \\
\text { cina }\end{array}$ & Khas lidah buaya & Khas lidah buaya & Khas lidah buaya \\
\hline & Bentuk & Semi solid & Semi solid & Gel mengerut & Gel mengerut & $\begin{array}{c}\text { Berjamur sangat } \\
\text { banyak }\end{array}$ \\
\hline & Rasa & Licin & Licin & Licin & Licin & 5 \\
\hline
\end{tabular}

\section{Hasil uji daya sebar}

Hasil uji daya sebar dapat dilihat pada tabel di bawah ini :

Tabel 5 Hasil Uji Daya Sebar

\begin{tabular}{|l|c|c|c|c|}
\hline \multirow{2}{*}{ Suhu } & \multirow{2}{*}{ Waktu } & \multicolumn{3}{|c|}{ Daya sebar } \\
\cline { 3 - 5 } & & FI & F II & F III \\
\hline \multirow{2}{*}{ Kamar $\left(15-30^{\circ} \mathrm{C}\right)$} & Hari ke-0 & $4 \mathrm{~cm}$ & $6,3 \mathrm{~cm}$ & $6,5 \mathrm{~cm}$ \\
\hline Dingin $\left( \pm 4^{\circ} \mathrm{C}\right)$ & Hari ke-3 & $6 \mathrm{~cm}$ & $5 \mathrm{~cm}$ & $3,4 \mathrm{~cm}$ \\
\hline
\end{tabular}

\section{PEMBAHASAN}

\section{Formulasi}

Berdasarkan uji organoleptik pada hari ke-0 (sesaat setelah proses pembuatan), F I memiliki kriteria yang mendekati dengan karakteristik gel yaitu semi solid, tidak kaku, dan tidak lengket. FII dan F III cenderung lebih encer karena penggunaan gel lidah buaya yang lebih banyak. Menurut Eshun (2004), gel lidah buaya mengandung 98,5\% 
air sehingga wajar apabila semakin banyak penggunaan gel lidah buaya maka sediaan cenderung semakin encer.

\section{Uji susut pengeringan}

Berdasarkan pengamatan pada Tabel 2 , diperoleh rata-rata persentase hasil susut pengeringan sebesar $3,77 \%$, di mana hasil susut pengeringan dinyatakan memenuhi persyaratan karena kadar air yang terkandung di dalam simplisia kurang dari $10 \% \cdot{ }^{[12]}$

\section{Uji stabilitas fisik}

Uji stabilitas yang dilakukan pada penelitian ini adalah uji stabilitas pada suhu kamar $\left(15-30^{\circ} \mathrm{C}\right)$ dan pada suhu dingin $\left( \pm 4{ }^{\circ} \mathrm{C}\right)$. Pengamatan dilakukan setiap hari mulai hari ke-0 sampai hari di mana gel ditumbuhi oleh jamur.Berdasarkan hasil uji, Gambar 1 dan Gambar 2 menunjukan penurunan $\mathrm{pH}$ selama penyimpanan. Hal ini sesuai dengan hasil penelitian sebelumnya di mana rata-rata $\mathrm{pH}$ setiap minggu (minggu ke-0 sampai minggu ke-8) mengalami penurunan.[2]

Penurunan pH pada suhu kamar (15$30^{\circ} \mathrm{C}$ ) lebih cepat dibandingkan $\mathrm{pH}$ pada suhu dingin $\left( \pm 4^{\circ} \mathrm{C}\right)$. Hal ini membuktikan bahwa faktor lingkungan seperti suhu dapat mempengaruhi $\mathrm{pH}$ sediaan. Suhu kamar adalah suhu optimum bagi pertumbuhan jamur atau kapang sehingga dapat meningkatkan proses metabolisme. Sebaliknya, suhu rendah dapat mengganggu proses metabolisme karena menyebabkan cold shock dan freezing. Metabolisme yang dilakukan oleh jamur atau kapang terhadap polisakarida yang terkandung dalam lidah buaya menghasilkan asam organik sehingga mengakibatkan penurunan $\mathrm{pH} .{ }^{[13][14][15]}$

Faktor lain yang mempengaruhi perubahan $\mathrm{pH}$ diantaranya penyimpanan yang kurang baik, jumlah atau konsentrasi gelling agent yang digunakan, dan lama penyimpanan. [13][16]

Adapun Tabel 3 dan Tabel 4 menunjukan hasil uji organoleptik sediaan pada suhu kamar $\left(15-30^{\circ} \mathrm{C}\right)$ dan suhu dingin $( \pm 4 \circ \mathrm{C})$. Berdasarkan pengamatan, semua sediaan gel telah dibuat berbentuk semi solid dengan aroma khas simplisia daun ketepeng cina, warna yang dihasilkan oleh gel simplisia daun ketepeng cina dari semua variasi adalah hijau kecoklatan. Bau dan warna dari sediaan tergantung banyaknya basis gel yang digunakan. Semakin banyak basis yang digunakan semakin pudar warna dan baunya. Selain itu, sediaan terasa licin ketika dipegang. Setelah beberapa hari, terjadi perubahan bentuk di mana gel seperti mencair pada suhu kamar dan mengkerut pada suhu dingin. Hal ini disebabkan oleh sineresis yang dipengaruhi suhu dingin dan lama penyimpanan [17][18][19]

Berdasarkan hasil pengamatan, sediaan mulai berjamur pada hari ke-4 (F I) dan hari ke-3 (F II dan F III) untuk suhu kamar $\left(15-30^{\circ} \mathrm{C}\right)$ dan pada hari ke-8 untuk semua formulasi pada suhu dingin $\left( \pm 4^{\circ} \mathrm{C}\right)$. Umumnya, jamur atau kapang suka tumbuh pada $\mathrm{pH}$ dibawah 7 dan tumbuh baik pada suhu kamar (mesofilik). Selain faktor tersebut, kapang atau jamur memerlukan air, sumber energi, sumber nitrogen, dan vitamin untuk pertumbuhan dan metabolisme.[20][21] Berdasarkan penelitian, gel lidah buaya mengandung asam amino, vitamin C, vitamin A, 98,5\% air, dan polisakarida sehingga kapang atau jamur dapat melakukan pertumbuhan dan metabolisme.[8][22][6]

Tabel 5 menunjukan hasil daya sebar yang dilakukan pada suhu kamar $\left(15-30^{\circ} \mathrm{C}\right)$ dan suhu dingin $\left( \pm 4^{\circ} \mathrm{C}\right)$. Pada suhu kamar, semakin tinggi jumlah basis gel, semakin rendah daya sebar gel sedangkan pada suhu dingin, semakin tinggi jumlah basis gel, semakin tinggi daya sebar gel. Faktor yang mempengaruhi daya sebar pada suhu kamar adalah jumlah basis gel, sementara faktor yang mempengaruhi daya sebar pada suhu dingin ialah sineresis yang disebabkan oleh suhu sehingga gel nampak lebih kecil dan padat.[23][17][18]

\section{SIMPULAN}

Hasil uji pH dan organoleptik yang dilakukan pada suhu kamar $\left(15-30^{\circ} \mathrm{C}\right)$ dan suhu dingin $\left( \pm 4^{\circ} \mathrm{C}\right)$ menunjukan hasil yang berbeda. Formula paling stabil "Gel Serbuk Simplisia Daun Ketepeng Cina (Cassia alata L.) Dengan Basis Gel Daun Lidah Buaya (Aloe vera L.)" diperoleh pada formula I yang mengandung 0,5 gram serbuk simplisia daun ketepeng cina dan 5 gram gel lidah buaya. Adapun formula yang stabil berdasarkan uji daya sebar, adalah formula 
II.

\section{DAFTAR PUSTAKA}

1. Gama, A. M. P., Subakir, S., \& Suhardjono, S. (2011). Perbandingan Ekstrak Daun Ketepeng Cina (Cassia alata, Linn.) Dengan Ketokonazol 2\% Dalam Menghambat Pertumbuhan Malassezia Furfur Pada Pityriasis Versicolor Secara In Vitro (Doctoral dissertation, Faculty of Medicine).

2. Sayuti, N. A. (2015). Formulasi dan uji stabilitas fisik sediaan gel ekstrak daun ketepeng cina (Cassia alata l.). Indonesian Pharmaceutical Journal, 5(2), 74-82.

3. Fardiaz, Srikandi, Ratih Dewanti, Slamet Budijanto. (1987). Risalah Seminar; Bahan Tambahan Kimia (Food additive). Dalam: Fujiastuti, T. \& Sugihartini, N. Sifat Fisik Dan Daya Iritasi Gel Ekstrak Etanol Pegagan (Centella asiatica L.) Dengan Variasi Jenis Gelling Agent. Jurnal Farmasi.

4. Kulkarni, T. G., Gowthamarajan, K., Rao, G. B., \& Suresh, B. (2002). Evaluation of binding properties of selected natural mucilages.

5. Kulkarni Vishakha, S., Butte Kishor, D., \& Rathod Sudha, S. (2012). Natural polymers-A comprehensive review. International Journal of Research in Pharmaceutical and Biomedical Sciences, 3(4), 1597-1613.

6. Surjushe, A., Vasani, R., \& Saple, D. G. (2008). Aloe vera: a short review. Indian journal of dermatology, 53(4), 163.

7. Edo, T. (2017). Uji Daya Hambat Ekstrak Etanol Daun Ketepeng Cina (Cassia alata) Terhadap Pertumbuhan Jamur Trichophyton Sp. Secara In Vitro. Jurnal Ilmiah Mahasiswa Veteriner, 1(1).

8. Ariyani, S. B., \& Hidayati, H. (2018). Penambahan Gel Lidah Buaya Sebagai Antibakteri Pada Sabun Mandi Cair Berbahan Dasar Minyak Kelapa. Jurnal Industri Hasil Perkebunan, 13(1), 1118.

9. Tranggono, R. I., dan F. Latifah. (2007). Buku Pegangan Ilmu Kosmetik. Dalam: Mappa, T., Edy, H. J., \& Kojong, N. Formulasi gel ekstrak daun sasaladahan (Peperomia pellucida (L.) HBK) dan uji efektivitasnya terhadap luka bakar pada kelinci (Oryctolagus Cuniculus). Pharmacon.

10. Dewi, R. K., (2010). Optimasi Formulasi Mikroemulsi Sediaan Hormon Testosteron Undekanoat

11. Garg, A. D., Aggarwal, S., and A. K. Sigla. (2002). Spreading of Semisolid Formulation. Technology Pharmaceutical. Dalam: Mappa, T., Edy, H. J., \& Kojong, N. Formulasi gel ekstrak daun sasaladahan (Peperomia pellucida (L.) HBK) dan uji efektivitasnya terhadap luka bakar pada kelinci (Oryctolagus Cuniculus). Pharmacon.

12. Indonesia, D. K. R. (2008). Farmakope Herbal Indonesia. Edisi I. Jakarta: Departemen Kesehatan RI.

13. Astuti, D. P., Husni, P., \& Hartono, K. (2017). Formulasi dan Uji Stabilitas fisik Sediaan Gel Antiseptik Tangan Minyak Atsiri Bunga Lavender (Lavandula angustifolia Miller). Farmaka, 15(1), 176-184.

14. Jo, W. S., Park, H. N., Cho, D. H., Yoo, Y. B., \& Park, S. C. (2011). Optimal Media Conditions For The Detection of Extracellular Cellulase Activity In Ganoderma Neo-Japonicum. Mycobiology, 39(2), 129-132.

15. Wathoni, N., Rusdiana, T., \& Hutagaol, R. Y. (2009). Formulasi gel antioksidan ekstrak rimpang lengkuas (Alpinia galangal L. Willd) dengan menggunakan basis aqupec 505 HV. Farmaka, 7(1), 1527.

16. Septiani, S. (2012). Formulasi sediaan masker gel antioksidan dari ekstrak etanol biji melinjo (Gnetun gnemon Linn.). Students e-Journal, 1(1), 39.

17. Imeson, A. P. (2009). Carragenan And Furcellaran. Dalam: Prakarsa, A. W. Pengaruh Perbedaan Tepung Labu Kuning Dalam Produk Jelly Ditinjau Dari Karakteristik Fisikokimia Dan Sensori. (Doctoral dissertation, Universitas Katolik Soegijapranata Semarang).

18. Kuncari, E. S., Iskandarsyah, I., \& Praptiwi, P. (2014). Evaluasi, Uji Stabilitas Fisik Dan Sineresis Sediaan Gel Yang Mengandung Minoksidil, Apigenin Dan Perasan Herba Seledri (Apium graveolens L.). Buletin 
Penelitian Kesehatan, 42(4 Des), 213222.

19. Gaman, P.M., Sherrington,K.B. (1994). Ilmu Pangan: Pengantar Ilmu Pangan, Nutrisi Dan Mikrobiologi. Dalam: Prakarsa, A. W. Pengaruh Perbedaan Tepung Labu Kuning Dalam Produk Jelly Ditinjau Dari Karakteristik Fisikokimia Dan Sensori. (Doctoral dissertation, Universitas Katolik Soegijapranata Semarang).

20. Gandjar, I. (2006). Mikologi dasar dan terapan. Yayasan Obor Indonesia.

21. Ika, Hidayati Permata. 2016. Diklat Kuliah Mikrobiologi Dasar. Malang
22. Eshun, K., \& He, Q. (2004). Aloe vera: a valuable ingredient for the food, pharmaceutical and cosmetic industries-a review. Critical reviews in food science and nutrition, 44(2), 91-96.

23. Afianti, H. P., \& Murrukmihadi, M. (2015). Pengaruh Variasi Kadar Gelling Agent HPMC Terhadap Sifat Fisik dan Aktivitas Antibakteri Sediaan Gel Ekstrak Etanolik Daun Kemangi (Ocimum basilicum L. forma citratum Back.). Majalah Farmaseutik, 11(2), 307-315 